\title{
Contextual cues and memory retrieval in rats: Alleviation of forgetting by a pretest exposure to background stimuli
}

\author{
BERNARD DEWEER \\ Laboratoire de Physiorogie Nerveuse, Département de Psychophysiologie, \\ Centre National de la Recherche Scientifique 91190 Gif-sur-Yvette, France \\ SUSAN J. SARA \\ Centre for Experimental and Comparative Psychology, University of Louvain, 3041 Pellenberg, Belgium \\ and

\begin{abstract}
BERNARD HARS
Laboratoire de Physiologie Nerveuse, Département de Psychophysiologie, Centre National de la Recherche Scientifique, 91190 Gif-sur-Yvette, France
\end{abstract}

\begin{abstract}
With a relatively complex maze, reliable forgetting is clearly seen when the training-test interval is 25 days. This forgetting is evidenced by the longer time taken to run the maze and in an increase in the number of errors from the last training trial to the first test trial. In this case, forgetting is a lapse, not a loss, since performance attains the last training trial level at a subsequent test. Furthermore, a reminder which does not in itself contain sufficient information to facilitate performance of a naive animal, significantly improves maze performance of animals which have "forgotten," even on the first retention test. With the use of additional control groups, it is shown that there must be a memory lapse before contextual cues can be demonstrated to be effective in facilitating memory retrieval.
\end{abstract}

The importance of context (extra list retrieval cues) in information retrieval has long been recognized in human subjects (see review by Tulving \& Thompson, 1973). Recent studies suggest that contextual cues play a role in the retrieval of memory in nonhuman subjects as well (Hickis, Robles, \& Thomas, 1977; Spear, 1971, 1973; Tomie, 1976). Animal memory studies, using such diverse techniques as experimental amnesia (Quartermain, McEwen, \& Azmitia, 1972; Sara, 1973), proactive interference (Spear, 1971), or spontaneous forgetting (Gatti, Pais, \& Weeks, 1975), have shown that the attributes found in the experimental environment can be extremely important in retrieval of weak memories. A recent study of spontaneous forgetting in very young rats has corroborated the importance of contextual cues in reinstatement of memory in animals (Haroutunian \& Riccio, 1977).

The present series of experiments examines the effects of pretest presentation of background stimuli or cues on retrieval of a forgotten habit. The evaluation of the effects of environmental manipulations on retrieval processes requires a behavioral paradigm

Requests for reprints should be sent to B. Deweer or S. J. Sara, whose present address is: Division of Behavioral Neurology, New York University School of Medicine, 341 E. 25th Street, New York, New York 10016. in which significant forgetting over time can be clearly demonstrated, forgetting being defined as a performance decrement after a long training-test interval.

The "antimnemonic bias" in animal studies is evidenced by the relatively few studies concerning longterm retention (see Winograd, 1971, for a historical survey). What data are available are rather conflicting. The studies of retention, over years, of keypecking in pigeons (Skinner, 1950) have traditionally been cited as an example of the durability of welllearned habits. However, it has been pointed out that careful examination of Skinner's data reveals a good deal of forgetting (Spear, 1976). Nevertheless, in a recent study of retention of a negatively reinforced discrimination task in gerbils, the investigators concluded that "the original learning endured, unaffected by the passage of time" (Neylon \& Brosgole, 1974 , p. 514). In our own studies of the barpress response in rats, we have reported that, although forgetting was seen in response latencies, once the first response was emitted, performance continued at a level comparable to that of the last training session (Sara, David-Remacle, Weyers, \& Giurgea, 1979), thus indicating that the response measure is an important factor in evaluating forgetting (see also Sara, David-Remacle, \& Lefevre, 1975). 
Early studies by Anderson (1940) reported not only that rats did not forget maze habits over time, but that there was a spontaneous improvement in performance, the level of improvement increasing with the time between training and testing-the reminiscence phenomenon. More recently, reminiscence has been described in mice, using an appetitive barpress task (Jaffard, Destrade, Soumireu-Mourat, \& Cardo, 1974). Huppert and Deutsch (1969) found that in a partially learned escape task, there was first a reminiscence over time for up to 10 days after acquisition, followed by a gradual decline, a forgetting of the response. These authors take this biphasic retention function as evidence that memory traces are consolidated over a long time and that after this consolidation there is a decay of memory. Finally, Gleitman (1971) has attempted to compare long-term retention of different tasks, and denotes rather precisely what kinds of tasks are forgotten and what kinds are retained over time.

Since there is so little literature concerning longterm retention in the rat, and since the available studies indicate that retention is highly task-dependent, the present experiments evaluate retention of a relatively complex maze, to determine the extent to which spontaneous forgetting of this task occurs and if this forgetting is reversible by pretest cuing. We address ourselves to two questions: How much and what aspects of the task are actually forgotten? What is the nature of the forgetting? If a performance decrement is due mainly to progressive loss of information (trace decay), as Gleitman (1971) maintains, pretest reminders should not be effective in alleviating forgetting. On the other hand, if poor initial performance is a warm-up decrement due to retrieval failure, as Spear (1971) has proposed, then we might expect pretest cuing to facilitate retrieval.

\section{EXPERIMENT 1}

Pilot studies showed that a $90-\mathrm{sec}$ detainment in a wire-mesh cage next to the maze, with the concomitant availability of background stimuli present in the experimental room, was as effective a reminder as the startbox that had previously served as a memory reactivator in our amnesia studies (see Sara, 1973) and in Lewis and Bregman's (1973) reactivation experiments. The former was chosen as the preferred contextual reminder, since these pilot studies had indicated less interindividual variations with this procedure. To assure that any facilitative effect of the procedure was due to the cue value of the stimuli attended to during the 90 -sec delay, an attempt was made, in one of the control groups, to extinguish any association between the background stimuli and the subsequent response contingencies. These procedures-reminder and habituation to the reminder - have been used by Lewis and Bregman (1973) in their studies; they showed that exposure to the startbox before an amnestic treatment was sufficient to reactivate memory and make it vulnerable to the effects of electroconvulsive shock (ECS). The animals that were exposed to the startbox several times were not rendered amnestic by ECS, presumably because associations between the cues in the startbox and the subsequent maze response and reward had been extinguished, and thus the cues were no longer effective memory reactivators.

If the poor performance after a long training ttest interval was due to retrieval failure, as any reminder effect would suggest, one test trial should have been sufficient to reinstate the performance seen at the last acquisition trial. To test this hypothesis, all animals were retested a second time, 24-h after the first retention test.

Thus, this experiment examined (1) long-term retention of a complex maze task and (2) the effectiveness of a $90-\mathrm{sec}$ exposure to background stimuli in the experimental room as a reinstator of memory. To assure that the facilitative effect was due to the associative value of the cues available during this detainment period, these associations were extinguished in a control group prior to the testing session. Finally, to add support to the contention that forgetting is a "lapse" and not a "loss," all animals were retested $24 \mathrm{~h}$ later, using the same pretest procedure.

\section{Method}

Subjects. Fifty-seven male Sprague-Dawley rats, obtained from IFFA CREDO, St. Germain sur l'Arbresle, France, served as subjects. They weighed $220-240 \mathrm{~g}$ on arrival in the laboratory and were housed, by twos, in wire-mesh cages measuring $35 \times 21$ $x 18 \mathrm{~cm}$ for the duration of the experiment. Eight days after arrival, the rats were placed on a food-deprivation schedule in which the daily ration, given between 4 and 6 p.m., was gradually reduced to $10 \mathrm{~g}$ per day over 4 days. The animals were then maintained at $10 \mathrm{~g}$ per day during the training period. Under this regime, they continued to gain weight and weighed approximately $90 \%$ of their free-feeding weights at the end of the training period.

Apparatus. The maze consisted of four $50 \times 40 \times 35 \mathrm{~cm}$ units, with $10-\mathrm{cm}$ openings between them. A $25 \times 25 \times 35 \mathrm{~cm}$ startbox was separated from the first maze unit by a sliding door. The goalbox, of the same dimensions as the startbox, could also be closed by a sliding door. The choice point, or stem of the $T$, was located $15 \mathrm{~cm}$ from the entrance of each unit. The transverse of the $T$ was $25 \mathrm{~cm}$ from the choice point. The barriers in each unit of the maze could be changed from one side to the other; the maze configuration was RLLR or LRRL. The apparatus was located in a room adjacent to the room in which the animals were housed; the air-conditioning system was common to both rooms.

Procedure. The first 5 days consisted of a pretraining period, during which the rats were habituated to the maze and the experimental conditions. On Day 1 , individual rats were allowed 
to feed in the goalbox for two 20 -min periods. The food reward consisted of $.2 \mathrm{~g}$ rat pellets. On Day 2 , the rats, in gangs of six, were given $30 \mathrm{~min}$ free exploration of the entire maze, with the barriers removed and food pellets in the goalbox. On Day 3, using only the last maze unit, two rats at a time were trained to enter the goalbox. On Day 4, using only one unit between the startbox and the goalbox, pairs of rats were trained to leave the startbox and eat in the goalbox. The procedure on Day 5 was the same as on Day 4, except that the rats were trained individually.

Training began on Day 8. Barriers were placed at the appropriate points, and the path was changed to its mirror configuration for every other rat. Each animal was carried from the home cage to the experimental room and placed into the startbox; the door was then opened and the time it took for the rat to reach the goalbox was recorded, as were the number of incorrect choices and the number of retracings. The animals were allowed to eat in the goal box for $2 \mathrm{~min}$, before being removed and returned to the home cage. There were five training trials, with a $24-\mathrm{h}$ intertrial interval.

After training, the animals were divided into three matched groups, using criteria based on the last two trials (Acquisition Trials 4 and 5). These criteria were latency to leave the startbox, total time to run the maze, number of errors, and number of retracings. The animals were kept in the home cages with free access to food and water for the first part of the training-test interval. Seven days before retention testing, the gradual reduction in food was reintroduced, as before pretraining. Fourteen days before the scheduled retention test, the animals in the group for which retrieval cues were to be extinguished (Group $H$ ) were removed from the home cages individually and carried in the hand of the experimenter to the reminder cage, where they remained for $90 \mathrm{sec}$. They were then removed and returned in the same manner to their home cages. This was done once a day for 14 days. The other two groups were not handled during this period.

On the test day, 25 days after the last training trial, each rat was removed from the home cage and carried in the hand of the experimenter to the experimental room. The nonmanipulated controls (Group NM) were placed directly into the startbox, and the door was opened. For the rats in the reminded group (Group R) and the rats in the habituated group (Group $\mathrm{H}$ ), the individuals were placed in the wire-mesh cage next to the maze for $90 \mathrm{sec}$ and then removed and placed into the startbox, after which the door was opened. For all groups, the exact path traced by each animal, the errors made, and total time to run the maze were noted. Upon arrival at the goalbox, the rat was allowed to eat for 2 min and was then removed and returned to the home cage. All animals were later fed $10 \mathrm{~g}$ of rat chow. The animals were retested the next day under the same conditions; that is, the "reminded" and "habituated" groups were first placed in the wire-mesh cage for $90 \mathrm{sec}$, and nonmanipulated animals were placed directly into the startbox.

\section{Results and Discussion}

First test trial. The nonmanipulated control animals ran much more slowly and made more errors on the first retention test than they did at the last acquisition trial (see Figures 1a and 1b). Within-group comparisons showed this performance decrement to be significant, both in running times $[\mathrm{F}(1,36)=5.51, \mathrm{p}<.05]$ and in errors $[F(1,36)=4.26, p<.05]$. Animals that received pretest cuing (Group R) did not show such a performance decrement, the within-group comparisons showing nonsignificant differences, both for time $[\mathrm{F}(1,36)=$ $.25]$ and for errors $[F(1,36)=2.52]$.

Animals that were habituated to the reminder procedure (Group $\mathrm{H}$ ) also showed a significant performance decrement compared with the last training trial.

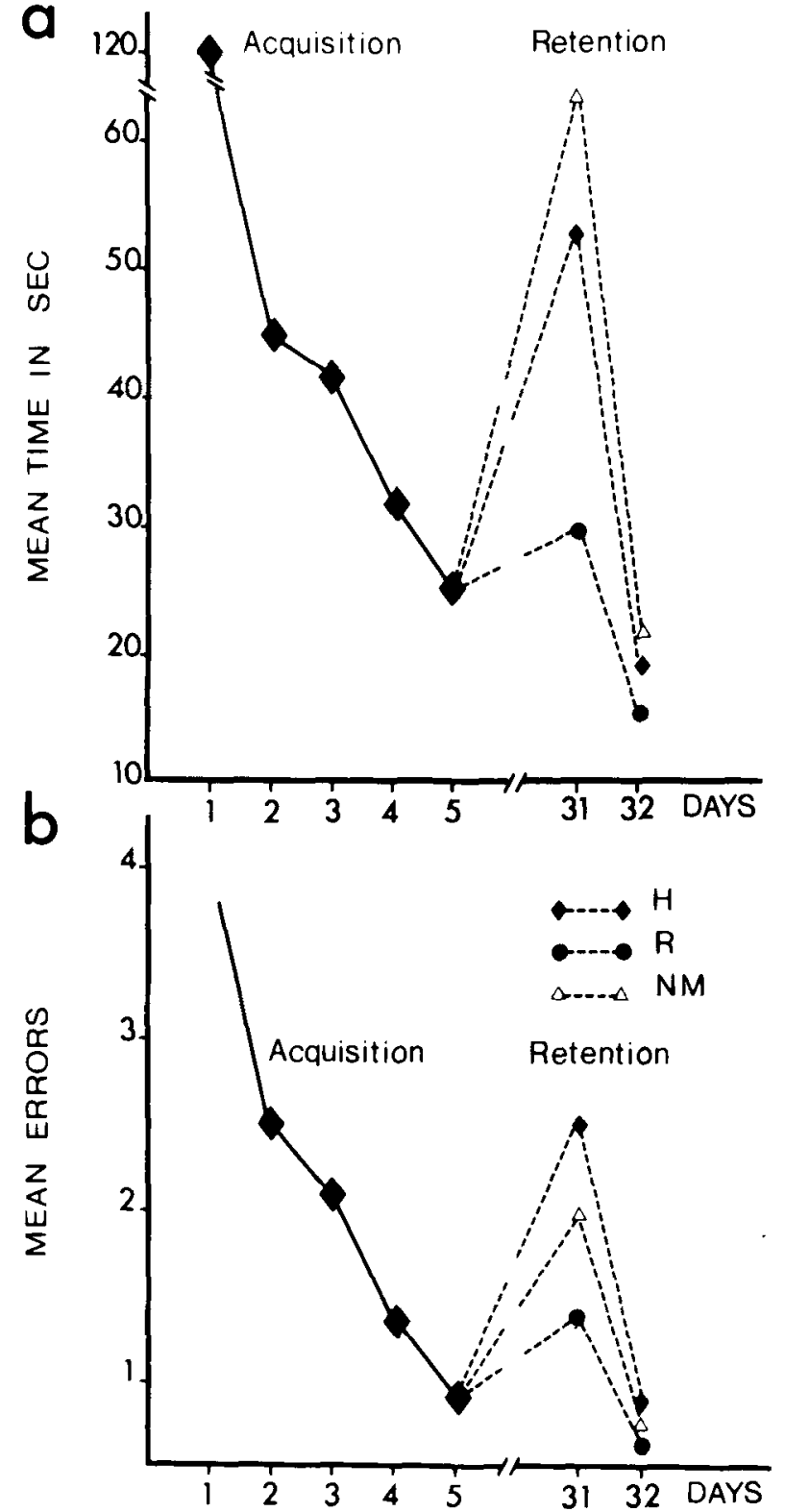

Figure 1. Mean time to run the maze (a) and mean number of errors (b) for the five training trials and the two retention tests. The training to Test 1 interval was 25 days; the Test 1 to Test 2 interval was $24 \mathrm{~h}$. Note the retention deficit in the two control groups (Group NM, nonmanipulated animals; Group $H$, animals habituated to the reminder) at Test 1 , and the recovery of performance at Test 2. The reminded animals (Group $R$ ) did not show this deficit.

Within-group comparisons indicated that this group made more errors $[F(1,36)=14.83, p<.005]$ and ran more slowly $[F(1,36)=5.17, p<.05]$ on Test 1 than at the end of acquisition. This performance decrement in Group $\mathrm{H}$ indicates that the 90 -sec delay per se is not sufficient to reinstate memory; the stimuli available in the experimental room must retain their associative value for the target memory. If this has been extinguished by repeated presentation of the room stimuli without subsequent presentation of the exper- 
imental apparatus and response contingencies, then there is no facilitation of retrieval at retention testing.

These within-group analyses show that there is significant forgetting in nonreminded animals and in animals habituated to the reminder. Pretest cuing alleviates this forgetting, as indicated by the lack of performance decrement on Test 1 in reminded animals. However, between-group differences at Test 1 failed to reach an acceptable level of significance when submitted to analysis of variance $[\mathrm{F}(2,54)=2.24$ for running times and $F(2,54)=1.71$ for errors].

Second test trial. When the animals were retested $24 \mathrm{~h}$ later, there was a significant improvement in performance in the two nonreminded groups (Figure 1). Within-group comparisons yielded significant differences between Tests 1 and 2 , both for running times $[F(1,36)=4.53, p<.05$, in Group $N M ; F(1,36)=$ $9.55, \mathrm{p}<.005$, in Group $\mathrm{H})$ and for errors $[\mathrm{F}(1,36)=$ $9.54, \mathrm{p}<.005$, in Group NM; $\mathrm{F}(1,36)=9.55$, $p<.005$, in Group H]. The improvement of performance was not significant in reminded animals between Tests 1 and $2[\mathrm{~F}(1,36)=2.38$ for running times and $F(1,36)=3.12$ for errors]. There was no difference, in any of the groups, between performance on the last training trial and Test 2; the first test and/or the reminder was sufficient to reinstaie performance observed, after five acquisition trials. This would support the hypothesis that forgetting is due to a lapse or retrieval failure rather than a total decay of memory.

\section{EXPERIMENT 2}

In the first experiment, within-group analyses showed significant forgetting and subsequent recovery on retest for the two control groups and an absence of forgetting in the reminded group. However, the between-group analyses did not reach an acceptable level of significance. This might be due to a floor effect; that is, the control groups did not show a sufficient degree of forgetting. In the second experiment, the task was made more difficult by adding two units to the maze used in Experiment 1; this would provide a more sensitive tool to evaluate forgetting.

This experiment also examined the effects of the pretrial manipulation on naive animals, in order to assure that this exposure to the background stimuli is a memory reinstater and does not merely facilitate performance in some general, nonspecific way. Pretest exposure to background stimuli should be ineffective on maze performance in acquisition or after a short training-test interval. Animals that received pretraining but were naive concerning the correct maze path were submitted to the "reminder" procedure for each daily trial, to assess any effect on the acquisition of the task. Finally, the design of this experiment allowed for the examination of the effects of reminder on trained animals after a 24 -h training-test interval.

\section{Method}

Subjects. Sixty rats, with the same characteristics and obtained from the same supplier as in Experiment 1, were used in this experiment. They were housed, handled, and food deprived as in the preceding experiment.

Apparatus. The maze was the same as that used in Experiment 1, except that two units were added and the configuration was LRRLLR or RLLRRL.

Experimental design and procedure. All animals were pretrained as in the preceding experiment. After pretraining, 30 animals were trained according to the schedule described in Experiment 1 . The other animals were maintained on the same food-deprivation schedule but were not handled. Trained animals were divided into two matched groups, reminded (T-R, trained-reminded) and nonreminded (T-NR, trained-nonreminded), according to the criteria used in the preceding experiment. After the 25-day trainingtest interval, both the trained and naive animals were tested in the maze (Days 31 and 32).

The naive group was randomly divided into a "reminded" (NT-R, nontrained-reminded) and nonreminded (NT-NR, nontrained-nonreminded) condition. The reminded animals (Groups T-R and NT-R) spent $90 \mathrm{sec}$ in the wire-mesh cage next to the maze immediately prior to each trial, while nonreminded individual rats (Groups T-NR and NT-NR) were carried by hand from the colony room and placed directly into the startbox, as in the previous experiment

The trained animals received two test trials, with a 24 -h intertrial interval, as in Experiment 1. Naive rats were trained for five daily trials, as the trained groups had been, except that half of these animals (Group NT-R) were submitted to the "reminder" procedure before each training trial.

The two nontrained groups continued the daily sessions for 5 days, so that the effects of the pretrial manipulation on acquisition could be evaluated. After these five sessions, the nonmanipulated group (NT-NR) was subdivided into two groups of seven animals each (one rat, a poor learner, was discarded), and individual rats were retested $24 \mathrm{~h}$ later under the cued or noncued condition. This was to evaluate the effect of the pretrial reminder on trained animals after a 24-h training-test interval.

Table 1 provides a summary of this experimental design.

Table 1

Experimental Design of Experiment 2

\begin{tabular}{|c|c|c|c|c|c|c|c|c|c|c|c|c|}
\hline Group & Pretraining & 1 & 2 & 3 & 4 & 5 & 31 & 32 & 33 & 34 & 35 & 36 \\
\hline$T \cdot \mathbf{R}$ & 00000 & 0 & 0 & 0 & 0 & 0 & $\mathbf{x}$ & $\mathbf{X}$ & & & & \\
\hline T-NR & 00000 & 0 & 0 & 0 & 0 & 0 & 0 & 0 & & & & \\
\hline NT-R & 00000 & & & & & & $\mathrm{X}$ & $\mathrm{X}$ & $\mathrm{X}$ & $\mathrm{x}$ & $\mathrm{x}$ & \\
\hline NT-NR & 00000 & & & & & & 0 & 0 & 0 & 0 & 0 & $\begin{array}{c}\mathrm{X} \\
0\end{array}$ \\
\hline
\end{tabular}

Note $-T-R=$ trained, reminded $T-N R=$ trained, nonreminded $N T-R=$ nontrained, reminded $; N T-N R=$ nontrained, nonreminded. $X=$ with reminder; $0=$ without reminder. 


\section{Results}

Control animals (Group T-NR, trained-nonreminded) took longer to run the maze and made more errors on Test 1 than on the last acquisition trial. Within-group planned comparisons for the T-NR group showed significant increases in errors $[F(1,28)=$ $6.56, p<.025)$ and in running times $[F(1,28)=30.97$, $p<.005]$. This result replicates the forgetting observed in Experiment 1 in nonmanipulated and habituated animals. For the reminded animals (T-R), the withingroup analysis for running times showed no significant increase on Test 1 compared with the last training trial $[F(1,28)=2.98]$, that is, alleviation of forgetting. For errors, this comparison even showed a significant improvement in performance from the last acquisition trial to the first test trial $[F(1,28)=6.04, p<.025]$. This difference in results, as compared with those of

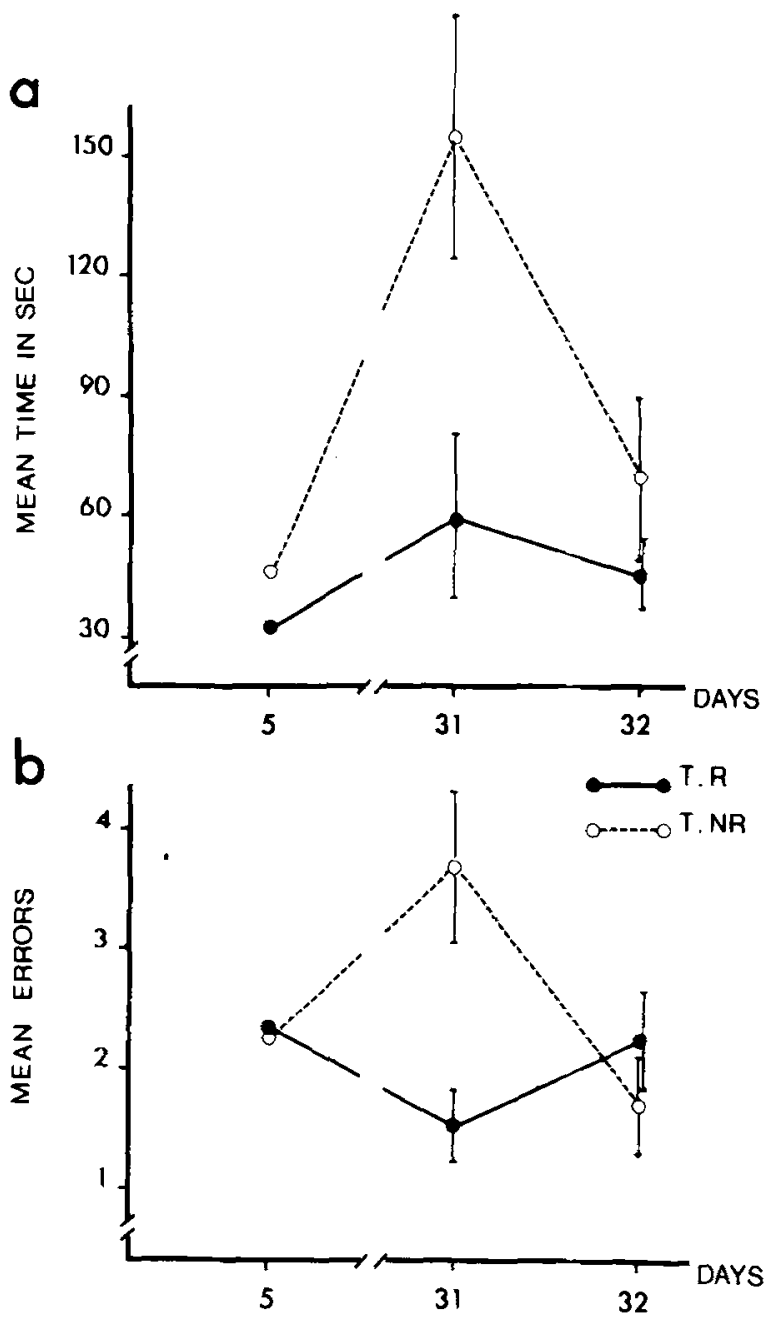

Figure 2. Running times (a) and errors (b) for the last acquisition trial, Tests 1 and 2 (mean \pm S.E.M.) for Irained groups (Group T-R, trained-reminded; Group T-NR, trained-nonreminded). The training to Test 1 interval was 25 days; the Test 1 to Test 2 interval was $24 \mathrm{~h}$. Note the retention deficit at Test 1 and recovery at Test 2 in nonreminded animals ( $a$ and $b$ ) and the alleviation of forgetting in reminded animals.

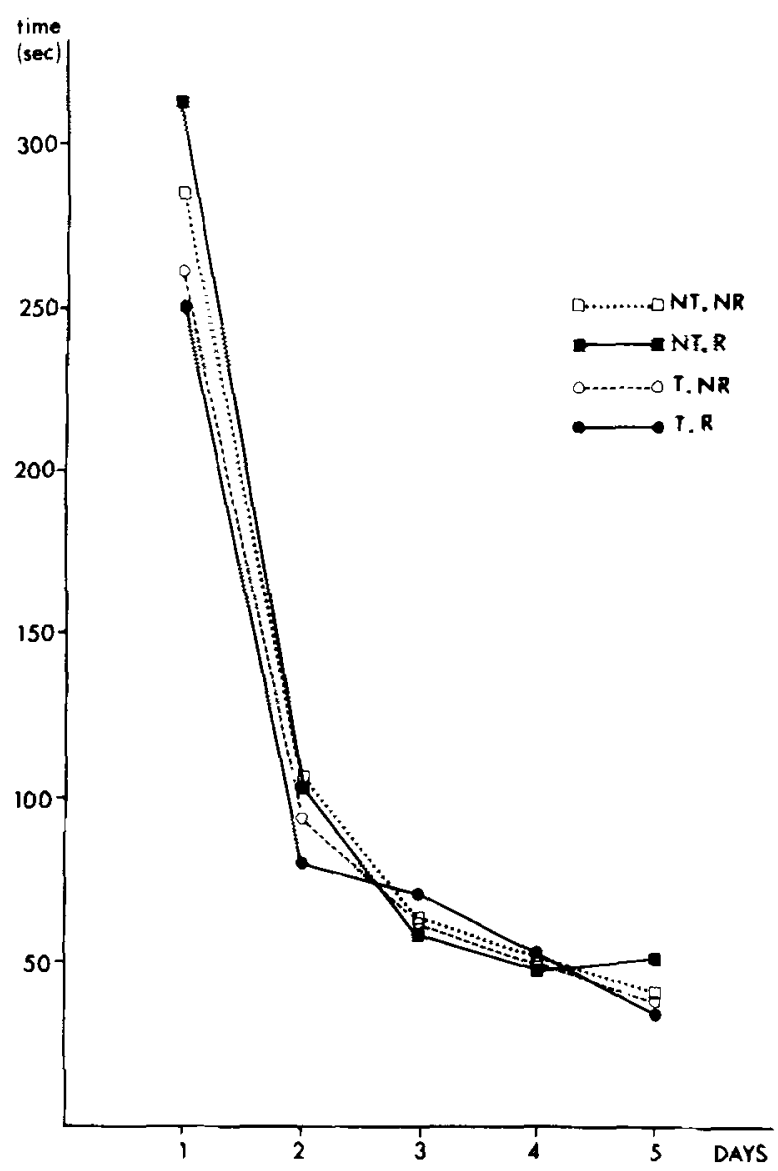

Figure 3. Acquisition curves for all groups (mean run limes). Note that there was no effect of the pretrial reminder manjpulation on acquisition (Group NT-R). Abbreviations: T, trained; $N T$, nontrained; $R$, reminded; NR, nonreminded.

Experiment 1, in which performances were not better on the first test than on the last acquisition trial in reminded animals, is probably a result of adding two units to the maze; animals had not, at the end of acquisition, reached the asymptote of their error performance in the more difficult task.

Mean and standard errors for running times and errors in these trained animals are given in Figure 2 ( $a$ and $b$ ).

Overall analysis of variance for the four groups (Day 31) was highly significant for both running times $[F(3,56)=12.52, p<.005]$ and errors $[F(3,56)=$ $41.66, p<.005]$. Between-group comparisons showed that differences beteween the trained-reminded $(T-R)$ and trained-nonreminded (T-NR) animals were significant for both errors $[F(1,28)=9.46, p<.005]$ and running times $[F(1,28)=6.59, p<.025]$. On the other hand, there was no effect of the reminder procedure on nontrained animals, for running times [NT-R/NTNR: $F(1,28)=.78]$ or for errors $[F(1,28)=.49]$. The mean running times for these groups on Day 31 (first acquisition trial) are shown in Figure 3, which depicts the acquisition curves for all groups. 
Table 2

Mean Scores and Standard Errors with a 24-h Training-Test Interval Under Cued or Uncued Conditions

\begin{tabular}{lrrrrr} 
& \multicolumn{2}{c}{ With Cues } & & \multicolumn{2}{c}{ Without Cues } \\
\cline { 2 - 3 } \cline { 5 - 6 } & Time & Errors & & Time & Errors \\
\hline Mean & 53.40 & 2.58 & & 45.28 & 2.86 \\
SE & 11.59 & .76 & & 8.79 & .59 \\
\hline
\end{tabular}

Comparisons of the two nontrained groups with the trained-nonreminded animals (NT-R + NT-NR/T-NR) indicated that $T-N R$ rats ran faster $[285,323$, and $153 \mathrm{sec}$, respectively, for Groups NT-R, NT-NR, and T-NR; $F(1,42)=14.44, p<.005]$ and made fewer errors $[7.13,8.20$, and 3.67 , respectively; $F(1,42)=$ $17.25, \mathrm{p}<.005]$ than naive animals on Day 31 . So, while there is significant forgetting in this group (as seen in the within-group analysis), there is also a residual effect of the previous training experience on Test 1 performance.

On the second test (Day 32), there was no significant difference between performances in the two trained groups, T-R and T-NR $[F(1,28)=1.26$ for running times and $F(1,28)=1.14$ for errors]. As in the preceding experiment, it seems that once memory has been reinstated by the first test trial, the pretest procedure has no apparent effect on subsequent performances (see Figures $2 \mathrm{a}$ and $2 \mathrm{~b}$, Day 32 ).

The reminder treatment had no effect on the nontrained animals at any stage of acquisition, as indicated in Figure 3, which shows the running times during learning. The comparison of the acquisition curves in the four groups (overall analysis of variance for repeated measures) failed to show any difference among these groups, either for running times $[\mathrm{F}(4,224)$ $=1.22]$ or for errors $[F(4,224)=.82]$. It is interesting to note that the long interval between pretraining and training did not seem to impair acquisition in the NT groups. Either the pretraining procedure had no effect on the subsequent acquisition or the information acquired during this period (e.g., presence of food in the goalbox) was resistant to time-induced forgetting.

Finally, the animals in the NT-NR group were submitted to a sixth training trial, under the reminded or the nonreminded condition. The mean running time and the mean errors in these subgroups can be seen in Table 2 . No statistical difference appeared between these subgroups $[F(1,12)=.44$ for time and .09 for errors], indicating that the reminder treatment had no effect on animals tested $24 \mathrm{~h}$ after training.

\section{GENERAL DISCUSSION}

\section{Forgetting as Retrieval Failure}

These experiments show that when rats are trained in a 4- or 6-unit linear maze and tested 25 days later, there is a significant retention deficit, as measured by both running times and errors. These results are not in agreement with the traditional belief that there is little or no forgetting in animals undisturbed between training and testing. Mackintosh (1974) points out that this belief "rests on a small core of truth, surrounded by a larger mass of casually reported and uncritically accepted data"' (p. 472). Moreover, forgetting occurred for both aspects of the task-the forward running aspect, as measured by run times, and the spatial discrimination aspect, as measured by errors. Note that these findings are not in accord with those of Gleitman (1971), who found clear forgetting as measured by run time in a straight alley, but little forgetting as measured by errors in a $T$ choice. Our retention deficit, however, was only partial, since there was some savings on the first retention test compared with the first acquisition trial, even in the nonreminded animals. Furthermore, at Test 1, the nonreminded trained animals performed significantly better than those animals for which Test 1 was, in effect, the first training trial.

When animals were retested $24 \mathrm{~h}$ later, performance recovered to the level seen after five training trials. Thus, the deficit seen at Test 1 might be described as a warm-up decrement (see Logan, 1960). Although warm-up decrement has been reported in the literature in experimental psychology for many years, there has never been any real agreement as to what underlies this poor initial performance after an interruption. Spear (Spear, Gordon, \& Martin, 1973) has suggested that warm-up decrement is due to a memory "lapse" or retrieval failure. Our experiments tend to support this view, since the "warm-up decrement" is not seen in those animals that received a reminder, in the form of contextual cues, immediately before the retention test.

The pretrial manipulation-90-sec exposure to the experimental environment-did not change initial maze behavior in naive animals. It had no effect at all on the rate of acquisition of the task. When the sixth (or test) trial occurred $24 \mathrm{~h}$ after training, no facilitation in performance was observed. The reminder procedure was effective only in those animals that had "learned and forgotten." From these data, we suggest that the observed forgetting in control animals is due to retrieval difficulties; the reminder procedure provides contextual cues which trigger or facilitate retrieval processes.

\section{Contextual Cues and Control of Behavior}

The fact that the 90-sec detainment period in the wire-mesh cage has reminder qualities is corroborated by other results in a similar paradigm (see Gatti, Pais, \& Weeks, 1975). In that experiment, the reminder consisted of placing the animals, immediately pretest, into a box resembling the goalbox; this treatment was significantly more effective in alleviating forgetting if the reminder box was located in the experimental room rather than in the adjoining room. These results, taken 
with our present findings and the experiments cited in the introduction, present clear evidence for the involvement of contextual cues in memory retrieval processes. In further support of this view is the fact that background stimuli are intimately related to even more simple learning situations, such as habituation and classical conditioning. For example, Wagner and his colleagues have obtained extinction of habituation by the use of intertrial exposure to the experimental environment (Wagner, Note 1). In that experiment, rabbits were habituated to a tone in a single session. Control groups showed a response decrement to the tone (i.e., retention of habituation) when tested $48 \mathrm{~h}$ later. An experimental group was submitted to the same treatment, except that on the intervening day the animals were exposed to the training environment in the absence of the tone. This resulted in "extinction" of the habituation when the rabbits were retested $24 \mathrm{~h}$ later. The exposure to the context of habituation alone produced this extinction, thus demonstrating that background stimuli were intimately involved in habituation.

There are also many examples in the classical conditioning literature of the control exerted by the experimental context on the conditioned response. Kupalov (1961) has demonstrated that an animal that is extinguished in an experimental room will continue to respond to the same CS in a different room. And even more dramatically, Asratyan (1961) has shown that an animal can be conditioned to respond to a $\mathrm{CS}$ as a positive stimulus in one room and as a negative stimulus in another room.

Another example of the importance of these background or contextual stimuli can be found in recent literature on learning after limbic lesioning. Passive avoidance deficits in animals with septal lesions can be completely eliminated by increasing the availability of contextual cues during training and testing (Belgelloun, Burright, \& Donovick, 1977). Similar reports have been made for maze learning in rats with hippocampal lesions (Winocur \& Bindra, 1976; Winocur \& Beckenridge, 1973).

Our work suggests that the organizational processes that take place at the retention trial-that is, the integration of the information about current environmental demands, the CRs elicited by the experimental situation, and the previously stored information concerning response contingencies-are extremely labile. Memory retrieval, evaluated through performance measures, depends not only on the amount of information stored, but also on the perceptual and information processing activities occurring immediately prior to the retention test. This position is not unlike that of Tulving (1973), who holds that "remembering is regarded as a point product of information stored in the past and information present in the immediate cognitive environment of the rememberer"' (p. 352). There would seem to be a similarity between Tulving's position, based on cognitive analysis of verbal learning, and that of Wagner (Note 1), whose theoretical position is based mainly on observations taken from classical conditioning and habituation studies. Wagner proposes that "contextual cues may act via the associative network to excite stimulus representation in memory."

The results in our reminded groups lend support to both these positions. Contextual cues facilitate retrieval in amnestic animals (Sara, David-Remacle, \& Lefevre, 1975), in undertrained animals (e.g., Sara $\&$ Remacle, 1977) using a passive avoidance task, and in those animals exhibiting memory lapse after a long training-test interval, with a more complex task, as shown in the present experiments. The establishment of a reliable paradigm of animal forgetting makes it possible to approach the problem of the neurobiology of retrieval, an area which has not yet been widely studied.

\section{REFERENCE NOTE}

1. Wagner, A. Memory and habituation. Paper presented at the Memorial Conference for Jerzy Konorski, Mechanisms in learning and motivation, Sussex, 1977.

\section{REFERENCES}

Anderson, A. C. Evidences of reminiscence in the rat in maze learning. Journal of Comparative and Physiological Psychology, 1940, 30, 399-411.

Asratyan, E. A. The initiation and localization of cortical inhibition in the conditioned reflex arc. Annals of the New York Academy of Sciences, 1961, 92, 1141-1159.

Belgelloun, W., Burright, R., \& Donovick, P. Septal lesions, cue availability and passive avoidance acquisition by hooded male rats of two ages. Physiology \& Behavior, 1977, 18, 1033 1037.

Gatti, S. V., Pars, N., \& WeEks, J. R. Effect of reinstatement procedure on retention of differential appetitive responding. Bulletin of the Psychonomic Society, 1975, 6, 57-60.

Gleitman, H. Forgetting of long-term memories in animals. In W. H. Honig \& P. H. R. James (Ed.), Animal memory. New York: Academic Press, 1971.

Haroutunian, V., \& Riccio, D. Effect of arousal conditions during reinstatement treatment upon learned fear in young rats. Developmental Psychobiology, 1977, 10, 25-32.

Hickis, C. F., Robles, L., \& Thomas, D. R. Contextual stimuli and memory retrieval in pigeons. Animal Learning \& Behavior, $1977,5,16 i-168$

Hupper', F. A., \& Deutsch, J. A. Improvement of memory with time. Quarterly Journal of Experimental Psychology, 1969 , 21, 267-271.

Jaffard, R., Destrade, C., Soumireu-Mourat, B., \& Cardo, B. Time-dependent improvement of performance of appetitive tasks in mice. Behavioral Biology, 1974, 11, 89-100.

Kupalov, P. S. Some normal and pathological properties of nervous processes in the brain. Annals of the New York Academy of Sciences, 1961, 92, 1046-1053.

LEWis, D. J., \& BREGMAN, N. J. Source of cues for cuedependent amnesia in rats. Journal of Comparative and Physio. logical Psychology, 1973, 85, 421-426.

Log AN, F. A. Incentive. New Haven, Yale University Press, 1960. Mackintosh, N. J. The psychology of animal learning. London: Academic Press, 1974.

Neylon, A., \& Brosgole, L. Long-term forgetting of heat train- 
ing in mongolian gerbils. Psychological Reports, 1974, 34, 511 514.

Quartermain, D., McEwen, B. S., \& Azmitia, E. C. Recovery of memory following amnesia in the rat and mouse. Journal of Comparative and Physiological Psychology, 1972, 79, 360-370.

SARA, S. J. Progressive development of avoidance response after training, ECS, and repeated testing. Bulletin of the Psychonomic Society, 1973, 2, 134-136.

Sara, S. J., David-Remacle, M., \& Lefevre, D. Passive avoidance behavior in rats after electroconvulsive shock: Facilitative effect of response retardation. Journal of Comparative and Physiological Psychology, 1975, 89, 489-497.

Sara, S. J., \& Remacle, J. F. Strychnine-induced passive avoidance facilitation after electroconvulsive shock or undertraining: A retrieval effect. Behavioral Biology, 1977, 19, 465-475.

Sara, S. J., David-Remacle, M., Weyers, M., \& Giurgea, L. Piracetam facilitates retrieval but does not impair extinction of bar-pressing in rats. Psychopharmacology, 1979, 61, 71-75.

Skinner, B. F. Are theories of learning necessary? Psychological Review, 1950, 57, 193-216.

SPE AR, N. E. Forgetting as retrieval failure. In W. K. Honig \& P. H. R. James (Eds.), Animal memory. New York: Academic Press, 1971.

SPEAR, N. E. Retrieval of memory in animals. Psychological Review, 1973, 80, 163-194.
Spear, N. E. Retrieval of memories: A psychobiological approach. In W. K. Estes (Ed.), Handbook of learning and cognitive processes (Vol. 4) Attention and memory. Hillsdale. N.J: Erlbaum, 1976.

Spear, N. E., Gordon, W. C., \& Martin, P. A. Warm-up decrement as failure in memory retrieval in the rat. Journal of Comparative and Physiological Psychology, 1973, 85, 601-614.

Tomie, A. Retardation of autoshaping: Control by contextual stimuli. Science, 1976, 192, 1244-1246.

Tulving, E., \& Thompson, D. Encoding specificity and retrieval processes in episodic memory. Psychological Review, 1973, 80, 352-373.

Winocur, G., \& Beckenridge, C. B. Cue-dependent behavior of hippocampally damaged rats in a complex maze. Journal of Comparative and Physiological Psychology, 1973, 82, 512-522.

Winocur, G., \& Bindra, D. Effects of additional cues on passive avoidance learning and extinction in rats with hippocampal lesions. Physiology \& Behavior, 1976, 17, 915-920.

Winograd, E. Some issues relating animal memory to human memory. In W. K. Honig \& P. H. R. James (Ed.), Animal memory. New York: Academic Press, 1971.

(Received for publication April 30, 1979; accepted October 3, 1979.) 